\title{
Have we got the right focus in asthma care in general practice?
}

\author{
A qualitative study
}

Maithri Rupasinghe, Jennifer Reath, Biljana Cvetkovski, Sheree Smith, Sinthia Bosnic-Anticevich, Vicky Kritikos, Penelope Abbott

\section{Background and objective}

Asthma presentations are common in general practice, but opportunities to control asthma are often missed. The aim of this study was to explore how general practitioners (GPs) and practice nurses (PNs) deliver asthma care, with particular attention to perceived roles and challenges, and ways to improve management.

\section{Methods}

Using a qualitative approach, semistructured interviews were conducted with GPs and PNs working in an area of cultural diversity and socioeconomic disadvantage in western Sydney. Inductive thematic analysis was undertaken.

\section{Results}

Nineteen interviews were conducted, with nine GPs and 10 PNs. The main focus of asthma care was on acute presentations, with less emphasis on follow-up and preventive care and underuse of general practice chronic disease models of care. PN roles were generally limited to acute asthma assessment and triage. GPs did not commonly use spirometry or access non-GP specialist input.

\section{Discussion}

Asthma care in general practice may be improved by a greater focus on prevention and control, including through follow-up after acute presentations, enhanced collaboration between GPs and PNs, and supportive practice models.
IN AUSTRALIA, one in nine people reports having been diagnosed with asthma, with most asthma care delivered in general practice. ${ }^{1,2}$ However, opportunities to optimise the control of asthma are missed, including through poor adherence to asthma guidelines. ${ }^{3-5}$ Structural and knowledge barriers to asthma care delivered by general practitioners (GPs) have been identified, including time pressure, cost of spirometry and access to continuing medical education. ${ }^{4-6}$

Some of these barriers may be overcome by improving team care in asthma. Team work between GPs and practice nurses (PNs) enhances healthcare delivery; however, this can be impeded by a lack of clearly defined roles. ${ }^{7,8}$ Expanding the PN role may be challenged by the small business nature of Australian general practice and funding that does not support team care, and GPs not understanding PNs' practice scope..$^{9,10}$

To date, there has been little research examining GP and PN perspectives on delivering asthma care in general practice and how they could be supported to optimise management. This study was conducted in western Sydney, Australia, an urban region that includes some of the most disadvantaged suburbs in the state and where the burden of asthma is particularly high. ${ }^{1}$ This study explores how GPs and PNs deliver asthma care, with particular attention to their perceived roles and challenges, and consideration of ways to improve management.

\section{Methods}

This was a qualitative study employing semi-structured interviews. The research team comprised GPs working in clinical practice and academic roles, and researchers with backgrounds in nursing, pharmacy, respiratory medicine and qualitative research. All had experience in delivering asthma care. Ethical approval was obtained from the Human Research Ethics Committee, Western Sydney University (H 13404).

Convenience and snowball sampling was used to recruit GPs and PNs. Email invitations were sent to general practices affiliated with the teaching program of the Department of General Practice, Western Sydney University, and study participants referred by colleagues. Participants were drawn from western Sydney, an area of high cultural diversity and pockets of social and economic disadvantage, where there is high use of general practice services. ${ }^{11}$

All interviews were conducted by the lead researcher, who had no prior affiliation with participants, over a period of three months in 2019. An interview guide was devised, based on the literature on asthma care and healthcare delivery in general practice and research team expertise (Table 1). The interviews were semi-structured, with participant-led content encouraged. Focused probes were added as the data collection proceeded to further explore themes identified in the ongoing analysis. Interviews were recorded and then transcribed, and the 
de-identified data were managed using NVivo 12 software (QSR International).

Reflexive, data-driven thematic analysis ${ }^{12,13}$ was undertaken, underpinned by a grounded theory approach and recognition of the effect of the research team on the research. This included recognition that the research team members had a special interest in asthma care, and brought their understandings to the research findings. The analysis involved multiple stages, including independent coding of early transcripts by three team members, subsequent iterative coding of the whole dataset by MR, review of the dataset by multiple team members, identification of themes and subthemes, memo-writing, and refinement through group discussions into a finalised list of themes. Interviews were conducted until the researchers observed data saturation for key themes.

\section{Results}

Nineteen interviews, face to face (16) or by telephone (three), were conducted with GPs (nine) and PNs (10) from nine different general practices. Participants ranged in age from 25 to 59 years and varied in their engagement with asthma patients and the frequency with which they saw people with asthma (Table 2). Interviews ranged from 20 to 40 minutes, with a median duration of 32 minutes. The five themes identified in the analysis were the roles of GPs and PNs in asthma care, focusing on acute rather than chronic care of asthma, using spirometry, accessing and updating knowledge, and accessing additional medical opinion or care in asthma.

\section{Teamwork and discordant perceptions of roles in asthma care}

Asthma care was reported to be led by GPs, with the PN role generally limited to assessing and triaging patients with acute asthma and performing spirometry. Asthma action plans were completed by GPs without involvement of PNs. Some GP and PN participants recommended PNs should have a broader role, including delivering inhaler skill training and asthma education. PNs perceived they had limited time for this, given GP and practice priorities, whereas GPs saw lack of PN skills as the main barrier. Several PNs felt GPs did not recognise the value of their potential role in clinical management of asthma and that teamwork was suboptimal, to the detriment of patient care.

GPs are the decision makers. When [a] decision is made, the nurses and the staff should be able to do it, but some can't do it; there are few nurses who are senior nurses who know about these things but not the younger generation - it is very disappointing. (GP 3)

The services that GPs ask me to deliver to the patient, that's what I do. Practice nurses, they're good at doing clinical management. The more a PN is involved, the better that system gets... in the

\section{Table 1. Semi-structured interview guide}

\begin{tabular}{ll}
\hline Topic & Examples of probes \\
\hline $\begin{array}{l}\text { General practitioner/practice nurse role } \\
\text { in asthma }\end{array}$ & $\begin{array}{l}\text { Challenges, facilitators, expanding the role, } \\
\text { teamwork }\end{array}$ \\
\hline Approach to assessment/diagnosis & $\begin{array}{l}\text { Use of spirometry, challenges, facilitators, } \\
\text { strategies to improve }\end{array}$ \\
\hline Approach to management & $\begin{array}{l}\text { Acute asthma, chronic disease management, } \\
\text { patient education }\end{array}$ \\
\hline Approach to updating knowledge & $\begin{array}{l}\text { Guidelines, pharmaceutical industry, education } \\
\text { preferences, challenges, facilitators }\end{array}$ \\
\hline $\begin{array}{l}\text { Seeking additional care, specialist opinion } \\
\text { or guidance for patient care }\end{array}$ & \begin{tabular}{l} 
Processes, value, challenges \\
\hline
\end{tabular}
\end{tabular}

Seeking additional care, sp
or guidance for patient care

practices that I work, because I'm not highly involved in the patients' asthma care-so that's why that system is not happening for them. (PN 8)

\section{Focus on episodic acute asthma} GPs and PNs reported that the practice team was well organised in episodic acute management. However, patients with recurrent acute presentations were not usually engaged in preventive care. It was suggested that this could be due to a lack of consideration of the dangers of acute asthma and value of prevention by patients.

People, they don't take asthma disease as serious as the other chronic diseases ... because it's a common disease, especially from childhood, and I think, it's more about education, that people are not adequately educated that asthma can be very serious. (PN 8)

It was reported that when patients presented to the practice with acute asthma symptoms, GPs and PNs generally chose to use nebulisers instead of metered dose inhalers with spacers. This was seen as more acceptable to the patient and more time-efficient to the practice. GPs recognised this was a choice based on convenience rather than adherence to guidelines.

I would probably say most of them don't even need that level of nebulisation to be honest because they are only going to be mild, moderate, and nebulisations are usually reserved for the severe. But the problem, I guess, is convenience. (GP 1)

Nebuliser is easy for me. I give it to patients very frequently because I'm used to giving the nebuliser, not the spacer. [The] patient also feels good after [the] nebuliser. (PN 4)

Most participants believed that health system and practice factors also encouraged the prioritisation of acute asthma management. Funding in general practice was described as incentivising short consultations, which contributes to less consultation time spent on prevention and patient education. 


\section{Table 2. Participant sociodemographic characteristics}

\begin{tabular}{|c|c|c|}
\hline Participant characteristics & \multicolumn{2}{|c|}{ Number of participants $(n=19)$} \\
\hline \multicolumn{3}{|l|}{ Role } \\
\hline GPs & \multicolumn{2}{|c|}{9} \\
\hline PNs & \multicolumn{2}{|c|}{10} \\
\hline Gender & Male & Female \\
\hline GPs & 4 & 5 \\
\hline PNs & 0 & 10 \\
\hline
\end{tabular}

Years of experience range (years)

\begin{tabular}{lcccc}
\hline GPs & \multicolumn{5}{c}{$1-30$} \\
\hline PNs & \multicolumn{5}{c}{$1-20$} \\
\hline Frequency of asthma-related consultations & $\begin{array}{c}\text { Less } \\
\text { often }\end{array}$ & $\begin{array}{c}\text { Every } \\
\mathbf{2 - 3} \text { days }\end{array}$ & $\begin{array}{c}\text { Usually } \\
\text { once/day }\end{array}$ & $\begin{array}{c}\text { Several } \\
\text { times/day }\end{array}$ \\
\hline GPs & 2 & 4 & 2 & 1 \\
\hline PNs & 1 & 6 & 2 & 1 \\
\hline Practice billing characteristics & Number of general practice clinics (n = 9) \\
\hline Bulk billing (service covered by Medicare) & & & 6 & \\
\hline $\begin{array}{l}\text { Private fees (patient-claimed partial } \\
\text { reimbursement from Medicare) }\end{array}$ & & 3 & \\
\hline
\end{tabular}

$G P s$, general practitioners; $P N s$, practice nurses

The government is rewarding short high turnover, patient care rather than quality, comprehensive chronic conditions care. And if actually you spend half an hour and do your job really well, it will mean less flare-ups and they won't come back as often because you would have dealt with it properly and it's less cost to the health system. (GP 8)

While used by some, chronic disease care plans and follow-up systems for people with asthma were not usual. Most practices did not have a system for flagging and recalling patients with acute asthma presentations.

There's not a lot of incentive, financially, either, for the practice to prioritise recall for asthma. (GP 5)

For the other diseases, if they need to discuss it, there is a result with the doctor for the diabetes or other blood test results, [and] we always recall the patient. Otherwise, for asthma, I think I did not. (PN 4)

The culturally and linguistically diverse (CALD) backgrounds and poor health literacy of some patients regarding asthma were reported to compromise long-term management and adherence to preventer medications. Participants perceived that people from certain CALD backgrounds did not consider asthma as a chronic health problem, worried that they would become dependent on preventer medications and found a diagnosis of asthma to be stigmatising.

Most of them are first-time migrants, having grown up in different countries where the management of asthma might be very sporadic and fragmented and, with their own health literacy and ideas and cultural beliefs, a number of them are quite reluctant to use puffers because of the so-called dependence issue. (GP 2)
The biggest problem that I face is people are not accepting asthma, it is underdiagnosed, a lot of, you know, [ethnic groups], they take it as a social stigma, like they don't want to say I've got asthma. (GP 3)

\section{Spirometry}

A minority of general practices had spirometers, and spirometry was only done if a PN was available. It was most used in diagnosing chronic cough and differentiating between chronic obstructive pulmonary disease (COPD) and asthma. Facilitators of spirometry use were good PN staffing, availability through pathology collection centres, linkage to clinical management software, and availability of PN training in asthma at the primary health network. PNs reported being interested in performing spirometry, and found it assisted in patient education.

In the other practice ... they booked patients under me, I did spirometry for them ... The challenge [is] non-availability of spirometry, you know. I need to educate and train them on treatment for the asthma but I don't know whether the patient has COPD or asthma ... If we have a spirometry I perform it here. (PN 1)

Some GPs reported that they relied on clinical features for diagnosis of asthma and did not perceive spirometry to be of value. Barriers to its use were the cost of the spirometer; perceived lack of benefit; poor Medicare rebate; complexity of technique; and lack of trained nurses, clinic space and time required to perform spirometry.

We don't use spirometry in our practice. We diagnose asthma clinically with a good clinical history and clinical judgement. We used to have a spirometer. But the problem is that you need a nurse to do that. And then the other thing is that there is not enough rebate for spirometry. It's not enough, you know, for the time spent. (GP 4)

\section{Accessing guidelines and updating knowledge}

National Asthma Council online guidelines were the main reference source described by GPs. However, the complexity of the guidelines, and difficulties in navigating 
them, meant that finding the required information was difficult.

Guidelines, I guess because for different age groups there's a lot of different things there. Yes, I guess it is not as user friendly as it could be because there's a lot of, like, multiple links for all the separate subsets. It would be easy if you can have one simple, clear diagram. (GP 1)

GPs reported updating their knowledge through a variety of channels including pharmaceutical representative visits and workshops providing updates on asthma guidelines and new inhaler devices. GPs believed that HealthPathways,${ }^{14}$ an online information portal that provides clinical information to enhance patient management, was valuable.

The other things we use [in addition to on line guidelines] are pharmaceutical [representatives] coming in from time to time, and ... our usual resources in general practice, magazines, [and] HealthPathways, which is up there, which has very, very clear-cut guidelines. (GP 2)

PNs described limited education and training related to asthma, including spirometry, although they welcomed the opportunity for further training. They expressed interest in workshops and practice-based education, and identified that greater clinical responsibility for asthma would drive PN education.

I would say that I just follow whatever the doctors are telling to me to do, but they are not telling me why I should do that. I would say that I have less knowledge on asthma. I believe that nurses need to organise their education on asthma. Then we can help in diagnosis and management. (PN 4)

\section{Accessing additional medical opinion or care in asthma}

GPs perceived that non-GP specialist referral is rarely required and almost all asthma patients can be managed in general practices. Costs for private respiratory specialist consultations and waiting lists for hospital-based specialists were barriers to accessing specialist advice.
We use specialists just to reassure ourselves and to find out whether we've done everything right for the legal purpose. If something goes wrong, you know, we can get sued, so the only reasons why I send someone with asthma to a specialist is either on parents' request-or just to cover myself from legal problems, to check whether I have done everything right for a legal issue. In those instances only, I consult a specialist. [Otherwise] there is no need. (GP 3)

The patients, they're happier to see [a] GP, not a specialist, because first, they can't get [a specialist] appointment early. Second, it's the cost, it costs them much ... It takes a long time to get to see a specialist, unless they [have a] very severe problem. (PN 9)

Long outpatient wait lists were seen as a barrier to preventive asthma care. However, GPs reported use of emergency departments for acute asthma as a pathway to respiratory specialist advice.

\section{[The] public hospital setting is difficult} because of the waiting lists... We do have the asthma clinic there on hand for advice, and they will see the patient eventually, but there is a bit of a waiting time. I guess there would probably be more success [in timely access to specialist advice] if patients end up more often in [the emergency department]. (GP 1)

\section{Discussion}

GPs and PNs participating in this research reported multiple challenges in providing quality asthma care, despite it being a common condition in general practice. ${ }^{1}$ The present study provides insight into the challenges of managing asthma in an urban setting, in an area where a high population of culturally diverse, socioeconomically disadvantaged people receive asthma care in general practice. These challenges related to lack of teamwork, focus on acute asthma over chronic asthma care, low use of spirometry, inconsistent education and training access, and perceived limited need for non-GP specialist input.

The study highlights the persistence of a focus on treating acute asthma over controlling asthma in general practice, consistent with previous research. ${ }^{15}$ This appeared to be reinforced by patients and the general practice team. The interviewees believed the lack of focus on asthma control was driven to a large extent by their patients, who generally sought healthcare for acute presentations only. Those from CALD backgrounds were thought to be particularly likely to disagree with the concept of asthma as a chronic disease. Previous research into GP views about asthma and patients from CALD backgrounds who were Arabic-speaking also identified decreased self-management as a concern, along with the need to improve the cultural competence of healthcare professionals in managing asthma in CALD populations. ${ }^{16}$

People with asthma often overestimate the degree to which their asthma is controlled. ${ }^{17}$ Overuse of short-acting bronchodilators relative to preventer medications appears common. ${ }^{18}$ Promoting objective assessment by patients of their own asthma, self-management and understanding of the importance of controlling asthma is needed. ${ }^{19,20}$ Acute asthma presentations in general practice flag the need to review and improve control. However, the present study suggests that opportunities for this may continue to be missed.

The lack of follow-up after acute exacerbations of asthma in the present study accorded with previous research. ${ }^{6,21}$ In the present study, this appeared to be exacerbated by lack of practice systems for asthma and suboptimal collaboration within practice teams. Patients with frequent exacerbations could 'fall through the cracks' and not be adequately engaged in preventive care despite having unstable asthma. Asthma did not appear to be usually managed as a chronic health problem within existing chronic disease models of care, such as care plans and scheduled recalls and reminders. PNs have a pivotal role in managing other chronic conditions, ${ }^{22}$ yet in the present study were little used beyond acute management of asthma. Some GPs were not confident in the skills and training of PNs to take on a greater role; PNs spoke of not being enabled to contribute beyond 
acute asthma triage and treatment, which decreased motivation for training despite a perceived need. It appears that PNs may be a valuable resource to improve the systematic management of asthma within general practice and provide more patient education through role division.

The use of nebulisers for convenience in acute attacks - irrespective of severity and at variance with the guideline recommendation for use of spacers and reliever inhalers - may further distract from a chronic disease focus by reinforcing an emergency response. The lack of value GPs appeared to place on opinions from non-GP specialists may be further evidence that they were not thinking about asthma as a chronic disease. Additionally, spirometry was often seen by GP participants as being of limited value and the rebate for spirometry as providing inadequate recompense. However, up to one-third of patients with doctor-diagnosed asthma do not have asthma when objectively measured, ${ }^{23}$ and guidelines promote the routine use of spirometry in the diagnosis of asthma.

Education related to asthma was valued by GPs and PNs. Both groups recognised the National Asthma Council guidelines ${ }^{24}$ as the benchmark, though found it complex. The present study suggests asthma education for healthcare providers needs to include strong messaging around following up acute asthma presentations, including within a chronic disease model, to ensure optimal asthma control. HealthPathways ${ }^{14}$ may be of assistance in this goal. Similar focus in patient education is needed, including the importance of preventing acute asthma and countering the perceived need for nebulisation.

In terms of the healthcare system, the Australian general practice funding model and barriers to accessing non-GP specialist advice were seen to compromise quality in asthma care. Although longer consultations are associated with better decision making and resource usage, fee-for-service funding may incentivise throughput and inadequately support team-based care. ${ }^{25,26}$ Further, GPs often saw themselves as managing asthma without significant input from non-GP specialist colleagues. Consistent with other research, the present study showed that cost and long waiting lists inhibited referral to private and hospital non-GP specialists. ${ }^{27}$ However, the study suggests there was also a perception among GPs that non-GP specialist opinions were not commonly needed, which again may reflect a focus on episodic acute asthma care.

A limitation of this study was that it was undertaken in general practices affiliated with an academic general practice department, raising the possibility that participant interview responses were influenced by this relationship. This large pool of practices is commonly contacted for different research opportunities, which may ameliorate that risk. Another potential limitation was that it was restricted to one geographic region. However, this is also a useful aspect of research as it provides information on what is occurring in an area where there is high burden of asthma, high health needs, cultural diversity and socioeconomic disadvantage, and yet good availability of general practice care. The researchers have described the context of this region to assist readers to assess transferability of the findings.

\section{Conclusion}

This study has provided insight into the challenges encountered by GPs and PNs in assessing and managing asthma in an Australian setting. The research suggests that increased messaging around asthma as a chronic health issue to both patients and primary health care providers will help improve outcomes. At the general practice level, this includes improvements in flagging acute presentations; teamwork; the use of existing practice systems; and funding for chronic disease management such as care plans and recall systems, which encourage follow-up after acute asthma.

\section{Authors}

Maithri Rupasinghe MBBS, MRCGP (INT), MD (Family Medicine), FCGP, Visiting Fellow, Department of General Practice, Western Sydney University, NSW Jennifer Reath MBBS, MMed, PhD, FRACGP, Dip RANZCOG, GAICD, Foundation Peter Brennan Chair of General Practice, Western Sydney University, NSW Biljana Cvetkovski BPharm (Hons), MPharm (Research), PhD, Postdoctoral Research Fellow, Quality Use of Respiratory Medicines Use Group, Woolcock Institute, University of Sydney, NSW
Sheree Smith BNursing, MSocPlanningDevelopment, PhD (Public Health), PostGradCertHealthEcon, Professor, School of Nursing and Midwifery, Western Sydney University, NSW

Sinthia Bosnic-Anticevich BPharm (Hons),

PhD, Professor and Team Leader, Quality Use of Respiratory Medicines Use Group, Woolcock Institute, University of Sydney, Sydney Local Health District, NSW

Vicky Kritikos BPharm, MPharm (Clinical), PhD, GradCertEdStudies (Higher Education), Clinical Lead, Quality Use of Respiratory Medicines Group, Woolcock Institute of Medical Research, University of Sydney, NSW; Department of Respiratory and Sleep Medicine, Royal Prince Alfred Hospital, NSW

Penelope Abbott MBBS (Hons), MPH, PhD, Churchill Fellow, GAICD, FRACGP, Associate Professor, Department of General Practice, School of Medicine, Western Sydney University, NSW

Competing interests: SBA reports an unrestricted research grant on inhaler technique, and lecture and advisory board fees from Teva Pharmaceuticals, advisory board and lecture fees from AstraZeneca and Boehringer Ingelheim, lecture fees from GSK and consultancy fees from Sanofi and Mylan, outside the submitted work.

Funding: Department of General Practice, Western Sydney University, for payment of participants and transcription of interviews. The lead researcher (MR) was supported by a scholarship for his post-MD overseas training in family medicine by the Postgraduate Institute of Medicine, Sri Lanka, and the Ministry of Health, Sri Lanka.

Provenance and peer review: Not commissioned, externally peer reviewed.

Correspondence to:

P.Abbott@westernsydney.edu.au

\section{Acknowledgements}

The authors would like to acknowledge the general practitioners, practice nurses and practices who participated in the study, and Vicki Bradley and Sharon Lawrence, Western Sydney University, for administrative support.

\section{References}

1. Australian Institute of Health and Welfare. Cat. no. ACM 33. Canberra, ACT: AIHW, 2020. Available at www.aihw.gov.au/reports/chronic-respiratoryconditions/asthma/contents/asthma [Accessed 2 February 2021].

2. Britt H, Miller GC, Henderson J, et al. General practice activity in Australia 2014-15. General practice series no. 38. Sydney, NSW: Sydney University Press, 2015.

3. Barton C, Proudfoot J. Amoroso C, et al. Management of asthma in Australian general practice: Care is still not in line with clinical practice guidelines. Prim Care Respir J 2009;18(2):100-05. doi: 10.3132/pcrj.2008.00059.

4. Watkins K, Fisher C, Misaghian J, Schneider CR, Clifford R. A qualitative evaluation of the implementation of guidelines and a support tool for asthma management in primary care. Asthma Res Pract 2016;2:8. doi: 10.1186/s40733-0160023-9.

5. Heiner MM. Key barriers to optimal management of adult asthma in Australia: Physician and patient perspectives. Curr Med Res Opin 2007;23(8):1799-803. doi: 10.1185/030079907X210714.

6. Zwar NA, Comino EJ, Hasan I, Harris MF. General practitioner views on barriers and facilitators to 
implementation of asthma 3+ visit plan. Med J Aust 2005;183(2):64-67. doi: 10.5694/j.13265377.2005.tb06923.x.

7. Abbott $P$, Dadich $A$, Hosseinzadeh $H$, et al. Practice nurse and sexual health: Enhancing team care within general practice. Aust Fam Physician 2013;42(10):729-32.

8. Walker L. Practice nurses: Working smarter in general practice. Aust Fam Physician 2006;35(1-2):20-2.

9. Halcomb EJ, Salamonson Y, Davidson PM, Kaur R, Young SA. The evolution of nursing in Australian general practice: A comparative analysis of workforce. BMC Fam Pract 2014;15:52. doi: 10.1186/1471-2296-15-52.

10. Halcomb EJ, Salamonson Y, Cooper M, Clauson JL, Lombardo L. Culturally and linguistically diverse general practitioners' utilization of practice nurses. Collegian 2013;20(3):137-44. doi: 10.1016/j. colegn.2012.05.001.

11. Australian Institute of Health and Welfare. Healthy community indicators. Canberra, ACT: AIHW, 2020. Available at www.aihw.gov.au/reportsdata/indicators/healthy-community-indicators [Accessed 2 February 2021].

12. Braun $\mathrm{V}$, Clarke $\mathrm{V}$. Using thematic analysis in psychology. Qual Res Psychol 2006;3(2):77-101. doi: 10.1191/1478088706qp063oa.

13. Braun V, Clarke V. Reflecting on reflexive thematic analysis. Qual Res Sport Exerc Health 2019;11(4):589-97. doi: 10.1080/2159676X.2019.1628806.

14. Clinical Information Access Portal. NSW HealthPathways. Sydney, NSW: CIAP, 2021.
Available at www.ciap.health.nsw.gov.au/specialtyguides/nsw-healthpathways.html [Accessed 27 April 2021].

15. Cvetkovski B, Armour C, Bosnic-Anticevich S. Asthma management in rural New South Wales: Perception of health care professionals and people with asthma. Aust J Rural Health 2009;17(4):195-200. doi: 10.1111/j.14401584.2009.01071.x

16. Alzaye R, Chaar BB, Basheti IA, Saini B. General practitioners' experience of asthma management in culturally and linguistically diverse populations. J Asthma 2019;56(6):642-52. doi: 10.1080/02770903.2018.1472280.

17. Kritikos V. Price D, Papi A, et al. A multinational observational study identifying primary care patients at risk of overestimation of asthma control. NPJ Prim Care Respir Med 2019;29(1):43. doi: 10.1038/s41533-019-0156-4.

18. Azzi EA, Kritikos V, Peters MJ, et al. Understanding reliever overuse in patients purchasing over-thecounter short-acting beta ${ }_{2}$ agonists: An Australian community pharmacy-based survey. BMJ Open 2019;9(8):e028995. doi: 10.1136/bmjopen-2019028995.

19. Price D, David-Wang A, Cho SH, et al. Time for a new language for asthma control: Results from REALISE Asia. J Asthma Allergy 2015;8:93-103. doi: 10.2147/JAA.S82633.

20. Bosnic-Anticevich S, Kritikos V, Carter V, et al. Lack of asthma and rhinitis control in general practitioner-managed patients prescribed fixed-dose combination therapy in Australia. J Asthma 2018;55(6):684-94. doi: 10.1080/02770903.2017.1353611.
21. Rudolphy S. Asthma management in general practice - A chronic disease health priority. Aust Fam Physician 2008;37(9):710-14.

22. Young J, Eley D, Patterson E, Turner C. A nurseled model of chronic disease management in general practice: Patients' perspectives. Aust Fam Physician 2016;45(12):912-16.

23. Aaron SD, Vandemheen KL, FitzGerald JM, et al. Reevaluation of diagnosis in adults with physiciandiagnosed asthma. JAMA 2017;317(3):269-79. doi: 10.1001/jama.2016.19627.

24. National Asthma Council. Australian asthma handbook. South Melbourne, Vic: NAC, 2020. Available at www.asthmahandbook.org.au [Accessed 2 February 2021].

25. Heywood T, Laurence T. The general practice nurse workforce: Estimating future supply. Aust J Gen Pract 2018;47(11):788-95. doi: 10.31128/AJGP01-18-4461.

26. Sturmberg J, O'Halloran D, McDonnell G, Martin C. General practice work and workforce: Independencies between demand, supply and quality. Aust J Gen Pract 2018;47(8):507-13. doi: 10.31128/AJGP-03-18-4515.

27. Chung LP, Hew M, Bardin P, McDonald VM, Upham JW. Managing patients with severe asthma in Australia: Current challenges with existing model of care. Intern Med J 2018;48(12):1536-41. doi: 10.1111/imj.14103.

correspondence ajgp@racgp.org.au 